\title{
The COLIBRI experimental program in the CROCUS reactor: characterization of the fuel rods oscillator
}

\author{
Vincent Lamirand ${ }^{1,2 *}$, Pavel Frajtag ${ }^{1}$, Daniel Godat ${ }^{1}$, Oskari Pakari ${ }^{1}$, Axel Laureau ${ }^{1}$, Adolfo Rais ${ }^{1}$, \\ Mathieu Hursin ${ }^{1,2}$, Grégory Perret ${ }^{2}$, Carlo Fiorina ${ }^{1}$, Andreas Pautz ${ }^{1,2}$ \\ 1 Ecole Polytechnique Fédérale de Lausanne (EPFL) \\ 2 Paul Scherrer Institut (PSI) \\ *vincent.lamirand@epfl.ch
}

\begin{abstract}
The present article presents the mechanical characterization of the fuel rods oscillator developed for the purposes of the COLIBRI experimental program in CROCUS. COLIBRI aims at investigating the radiation noise related to fuel vibrations. The main motivation is the increased amplitudes in the neutron noise distributions recorded in ex- and in-core detectors that have been observed in recent years in Siemens pre-Konvoi type of pressurized water reactors. Several potential explanations have been put forward, but no definitive conclusions could yet be drawn. Among others, changes in fuel assembly or pin vibration patterns, due to recent modifications of assembly structural designs, were pointed out as a possible cause. Computational dynamic tools are currently developed within the Horizon 2020 European project CORTEX, to help with understanding the additional noise amplitude. The COLIBRI program is used for their validation. An in-core device was designed, tested, and licensed between 2015 and 2019 for fuel rods oscillation in CROCUS, in successive steps from out-of-pile tests with dummy fuel rods to critical in-core tests. The characterization of its mechanical behavior is presented, in air and in water, and as a function of the load, for safety and experimental purposes. The device allows simultaneously oscillating up to 18 fuel rods. The maximum oscillation amplitude is $5 \mathrm{~mm}$, while the maximum allowed frequency is $2 \mathrm{~Hz}$, i.e. in the frequency range in which the induced neutron flux fluctuations are most pronounced in nuclear power plants.
\end{abstract}

Keywords - Core monitoring and diagnostics, fuel vibration, noise analysis, research reactor experiment, zero-power reactor

\section{INTRODUCTION}

HE aim of the COLIBRI (CROCUS Oscillator for Lateral T

Increase Between $U_{\text {metal }}$ Rods and Inner zone) experimental program in CROCUS is to investigate the radiation noise related to fuel vibrations. It consists in carrying out experiments on rod displacement (static) and oscillation (dynamic) with a variation of both number and configuration of oscillated rods at relevant ranges of amplitudes and frequencies. The main motivation for this investigation is the increased amplitudes in the neutron noise distributions recorded in ex- and in-core detectors that have been observed in recent years in Siemens pre-Konvoi type of pressurized water reactors. Several potential explanations have been put forward, but no definitive conclusions could be drawn yet. Among others, changes in fuel assembly or pin vibration patterns, due to recent modifications of assembly structural designs, were pointed out as a possible cause. Such mechanical noise is suspected to arise from vibration of groups of fuel assemblies. Computational dynamic tools are currently developed at the Paul Scherrer Institute, as well as within the Horizon 2020 European project CORTEX [1], to help with understanding the additional noise amplitude. The COLIBRI program is used for their validation [2]-[4].

An in-core device was designed for fuel rods oscillation in CROCUS, and manufactured, tested, and licensed between 2015 and 2019 [5]. Limited modifications of core structures and fuel rods were required. Licensing and tests were conducted in successive steps from out-of-pile tests with dummy fuel rods to critical in-core tests. In this article, the tests of the fuel rods oscillator are presented, focusing on the mechanical characterization for safety and experimental purposes.

\section{EXPERIMENTAL SETUP OF COLIBRI}

In this part we briefly present CROCUS, and the mechanical design of the fuel rods oscillator for the COLIBRI program.

\section{A. The CROCUS reactor}

CROCUS at the École Polytechnique Fédérale de Lausanne (EPFL) is an experimental zero-power reactor, uranium-fueled and water-moderated, dedicated to teaching radiation and reactor physics, and to research [6]-[24]. A complete description of the reference core can be found in the International Reactor Physics Experiments Handbook (IRPhE) [25], [26]. It has been licensed for operating at a maximum power of $100 \mathrm{~W}$, i.e. a total neutron flux of $\sim 2.5 \cdot 10^{9} \mathrm{~cm}^{-2} \cdot \mathrm{s}^{-1}$ at the core center. Criticality is controlled either by water level using a spillway, or by two $\mathrm{B}_{4} \mathrm{C}$ absorber control rods, with an 
accuracy of $\pm 0.1 \mathrm{~mm}$ (equivalent to approximately $\pm 0.4 \mathrm{pcm}$ ) and $\pm 0.5 \mathrm{~mm}$ (up to $\pm 0.2 \mathrm{pcm}$ ), respectively. CROCUS operates at room temperature using a controlled water loop with secondary and tertiary circuits, two heat exchangers and an electrical heater.

The core is located in an Al-6060 grade vessel of $130 \mathrm{~cm}$ in diameter, $160 \mathrm{~cm}$ in height, and $1.2 \mathrm{~cm}$ in thickness. The vessel is filled with demineralized light water used as both moderator and reflector. The core active part has the approximate shape of a cylinder of $100 \mathrm{~cm}$ in height and about $60 \mathrm{~cm}$ in diameter. It consists of two interlocked fuel zones with square lattices of different pitches:

- $\quad$ an inner zone of $336 \mathrm{UO}_{2}$ rods with an enrichment of $1.806 \mathrm{wt} . \%$ and a pitch of $1.837 \mathrm{~cm}$;

- $\quad$ an outer zone of $176 \mathrm{U}_{\text {metal }}$ rods for these experiments, $0.947 \mathrm{wt} \%$ and $2.917 \mathrm{~cm}$;

- a varying water gap between the two zones because of the two different pitches.

A picture of the facility and core configuration is shown on Figure 1. Both uranium fuels consist of a 1-m pile of cylindrical pellets cladded in aluminum. The rods are maintained vertically by two octagonal aluminum grid plates spaced $1 \mathrm{~m}$ apart. In the COLIBRI program, the grids have a $1 \mathrm{~mm}$ cadmium layer to limit axial neutron leakage to the environment, i.e. structures activation, with the active zone of the fuel starting in the middle of the lower cadmium layer.

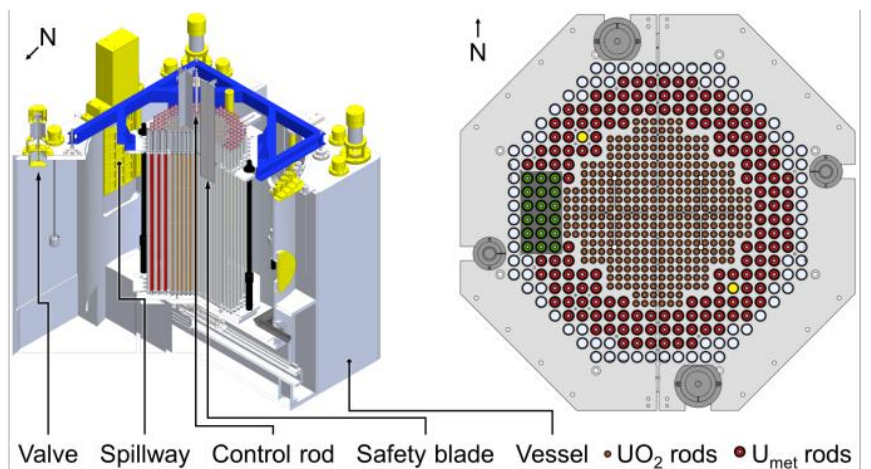

Fig. 1. View of the CROCUS reactor (left), and the core superior grid and configuration with the oscillation location ( $\mathrm{U}_{\text {met }}$ rods in green).

\section{B. Mechanical design of the fuel rods oscillator}

The fuel rods oscillator is designed to simultaneously oscillate any of 18 metallic uranium fuel rods laterally in the west region of the core periphery zone. Its design, development and licensing is presented in [5]. It consists of two moving plates set above and below the core grids, and rigidly connected by an aluminum beam (see Figure 2). Each plate carries an extremity of the fuel rods, top and bottom respectively. The top moving plate is fixed on the superior grid via gliders. Its oscillation is produced by a motor: the motor rotation is converted to a linear translation using an eccentric sheave and a rod. The oscillation is transferred to the bottom moving plate via the aluminum beam. The bottom moving plate is not constrained by gliders, it is therefore displaced only because of its connection to the transmission beam.

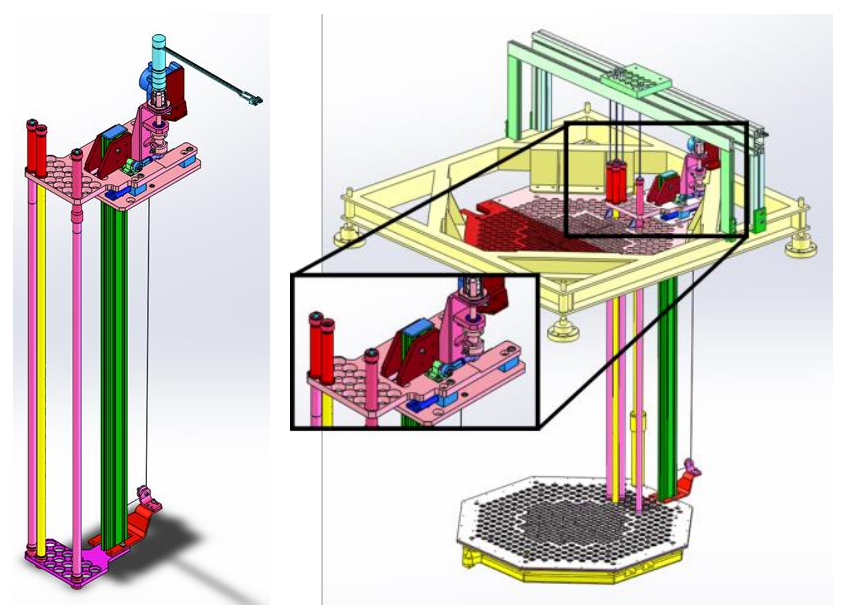

Fig. 2. The fuel rods oscillator alone (left) and with core structures and a few rods inserted in the device (right).

The selection of the moving fuel rods is performed by letting the rods lay on the reactor base plate (i.e. static), or suspend them up $10 \mathrm{~mm}$ above the base plate to insert them in the moving plates (i.e. moving). Top and bottom end caps are fixed to each rod to allow the insertion in the enlarged holes of either the static grids or the moving plates. Bumpers with soft rubber O-rings and hard metallic core are added to absorb any shock at the interface between grid and moving plate to prevent propagation to the fuel rods. The weight of the oscillating rods is supported by a platform. The amplitude of the oscillation is precisely tuned by changing the eccentricity of the sheave with calibration plates, 0.5 by $0.5 \mathrm{~mm}$ from 0 to $\pm 2.5 \mathrm{~mm}$ (i.e. $5 \mathrm{~mm}$ total) around their nominal positions in the lattice. Its frequency is depending on the speed of the motor.

The oscillation is controlled and monitored via a LabVIEWdeveloped software with $10 \mathrm{~ms}$ time-steps. An inductive captor is set at the rotation axis (i.e. at the top), which detects the actual movement of the motor by detecting the passage of four metallic pins per rotation. A cable coder is used to measure the displacement of the moving plate, i.e. at the bottom, with a $0.1 \mathrm{~mm}$ precision. The software produces a csv file output with the recordings of the motor position and speed, the signal of the inductive captor, and the position measurement of the cable. The inductive captor signal is also extracted for live and synchronized recording with the detection instrumentation. The motor, inductive captor, and cable coder are presented in Figure 3 , as well as a typical recording of an oscillation in Figure 4.

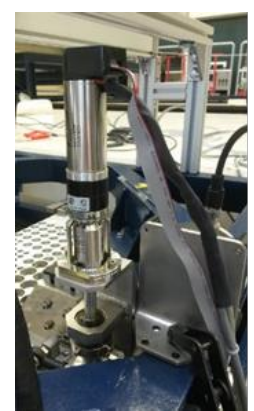

a)

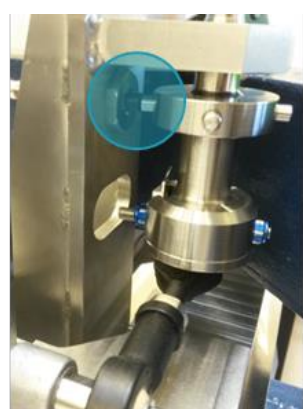

b)

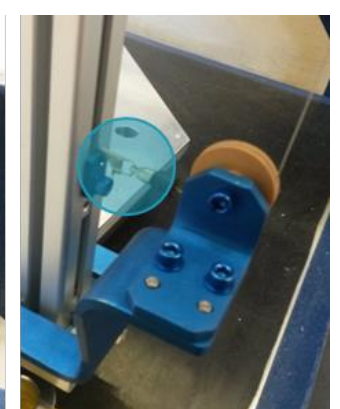

c)
Fig. 3. From left to right, a) setup of the motor on the rotation axis, b) inductive captor with a focus on the pin being read, and c) connection of the cable to the transmission beam. 

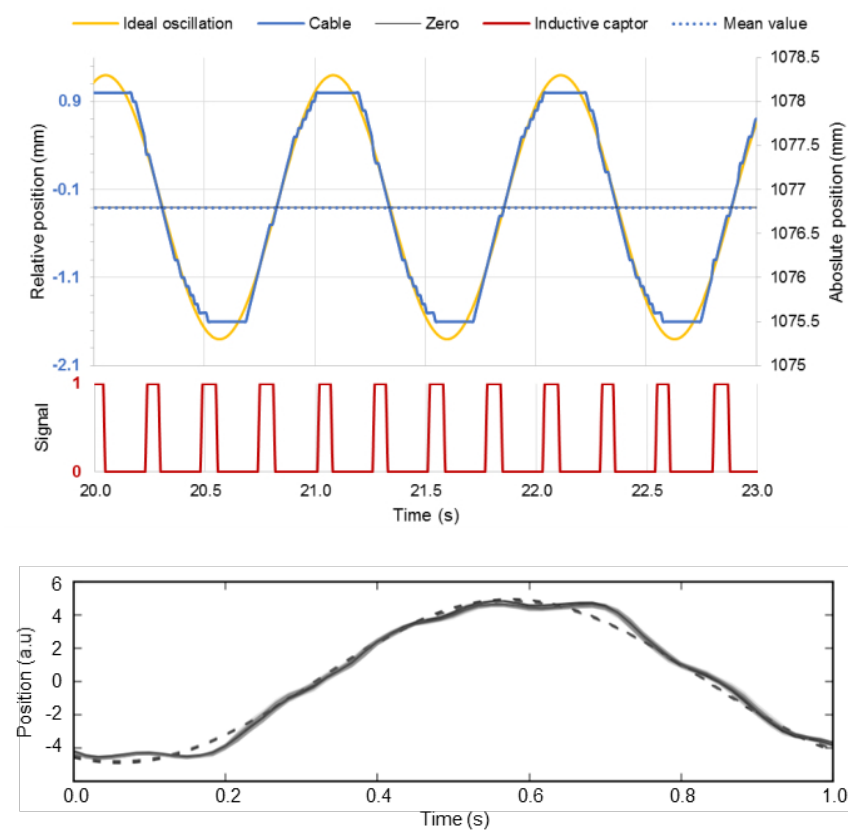

Fig. 4. Signals from one-rod oscillation in air, $\pm 1.5 \mathrm{~mm}$ and $1 \mathrm{~Hz}$ : on the top, signals from the cable (blue) and inductive captor (bottom, red) as provided by the control system; at the bottom, signal extracted from a video analysis.

\section{MECHANICAL CHARACTERIZATION OF THE OSCILLATOR}

\section{A. Motivation and means}

The aim of the mechanical characterization is to define operation limits for safety purposes, as well as to provide a knowledge of the introduced perturbation for the experiments. As the study was realized for commissioning purposes in the prospect of the oscillator's licensing, a strict step by step procedure was followed, defined in the authorization request and approved in the official authorization delivered by the Swiss regulator, IFSN/ENSI [27]. It is important to note that in the case of a safety shutdown in CROCUS, the water is dumped from the vessel to expansion tanks: the oscillator has to prove safe in both air and water conditions. In this prospect, the behavior of the oscillator has been characterized in air and in water, out-of-pile as a start and in-pile in the end, with empty, 1-rod and 18-rods loading.

At the top of the fuel rods, the transmission of the oscillation depends only on the rotation to translation conversion, and the limited plays associated. They were measured to be fixed with a dial gauge, and their impact is visible in Figure 4 on the flattening of the cable measurement (blue) as compared to an ideal sinus (yellow). Thus the present study focuses on the behavior at the bottom of the fuel rods, which is subject to transmission and inertia effects. The cable coder was used for measuring the oscillation, and determining its behavior in amplitude and frequency. The demonstration of the sufficiency of the cable coder proves important for the final in-pile operation. However, these data were complemented by video analysis for verification purposes when needed, mainly for frequency assessment, and identification of possible harmonics.

\section{B. Characterization in air, out-of-pile and in-pile}

The oscillator's behavior was characterized in air at amplitude and frequency ranges from 0.5 to $\pm 2.5 \mathrm{~mm}$, and 0.5 to $2.0 \mathrm{~Hz}$, respectively. The results are represented for both frequency and amplitude in Figures 5 and 6. The frequency results prove sound for all cases, as the set frequency corresponds to the measured one, and therefore, they are not discussed further.
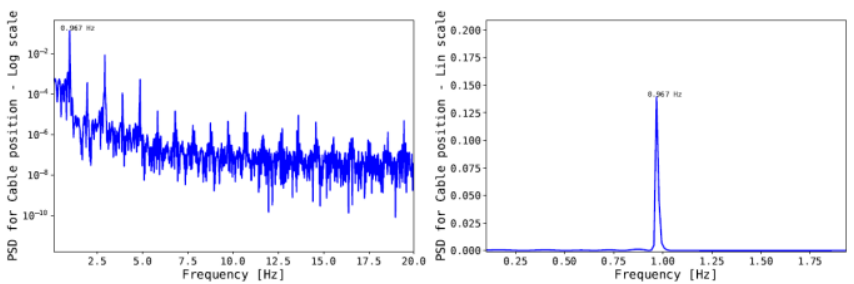

Fig. 5. Example of estimated power spectral density based on the cable data, for the same case than Figure 4 of 1 rod in air, $\pm 1.5 \mathrm{~mm}$ and $1 \mathrm{~Hz}$.

The tests empty-loaded proved to be representative of the top position, and thus were taken as a reference for comparison with loaded configurations. The tests with one rod demonstrated a behavior equivalent to the empty case within the $\pm 0.1 \mathrm{~mm}$ uncertainties. However, the tests with 18 oscillating rods demonstrated an increase of the measured amplitude with requested frequency and amplitude, i.e. applied force. As the increase quickly reaches a plateau, it seems that it is due to the compression of parts, and most probably the gliders, although they were selected for withstanding compression.
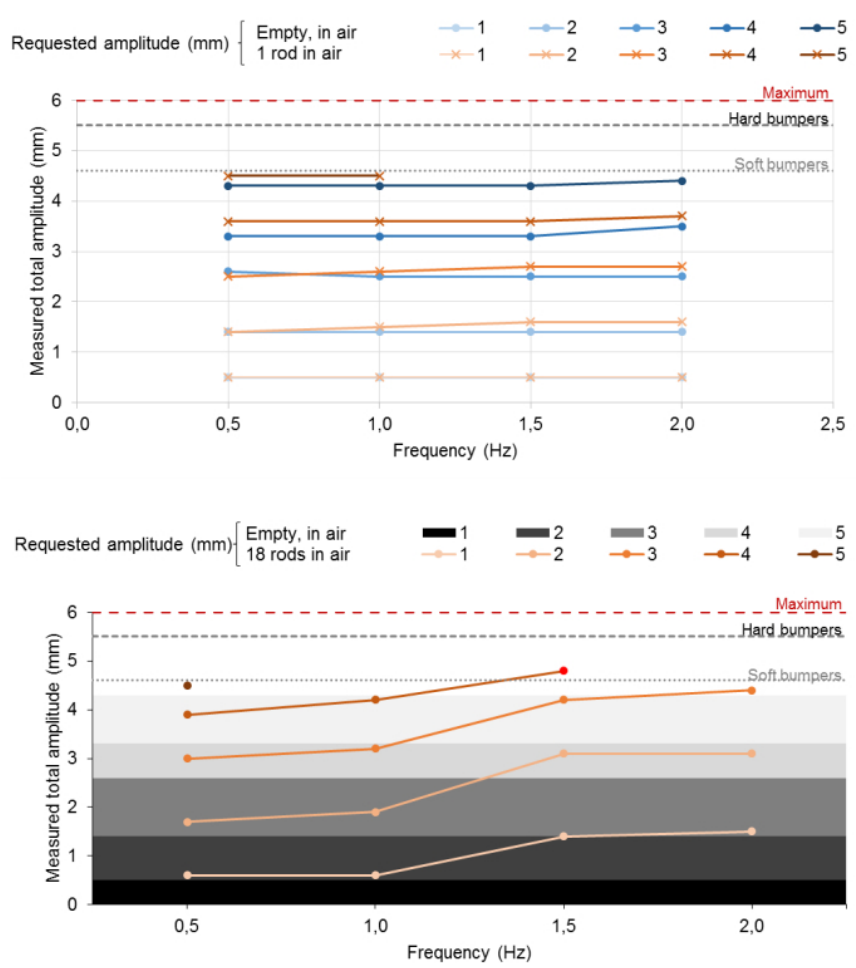

Fig. 6. Behavior of the oscillator in air, compared between empty- and onerod loads (top), and between empty- and 18-rods loads (bottom). The brilliant red dot at $4 \mathrm{~mm}$ and $1.5 \mathrm{~Hz}$ indicates the observed cushioning by the soft bumpers. The points are connected for readability purposes. 


\section{Characterization in water in-pile}

The tests were repeated in water in more details, and with a frequency range extended to the low frequency of $0.1 \mathrm{~Hz}$ for the 18-rods load. The results are presented in Figure 7 in comparison with the case in air. The oscillator behavior in air and in water is comparable within the uncertainties.

The addition of measured frequencies, and their extension to lower frequencies for 18 rods, shows that the amplitude increase stabilizes above a certain threshold. In addition, we observe that the increase is gradual when the requested amplitude is smaller. It supports the probable compression hypothesis. We also observe a general saturation for the $\pm 2.5 \mathrm{~mm}$ case, which confirms that the oscillation is limited by the bumper at this amplitude. As a consequence, it was proposed that the operation would be limited by the conservation of a stable oscillation shape, i.e. without observation of any bouncing on the soft bumpers.
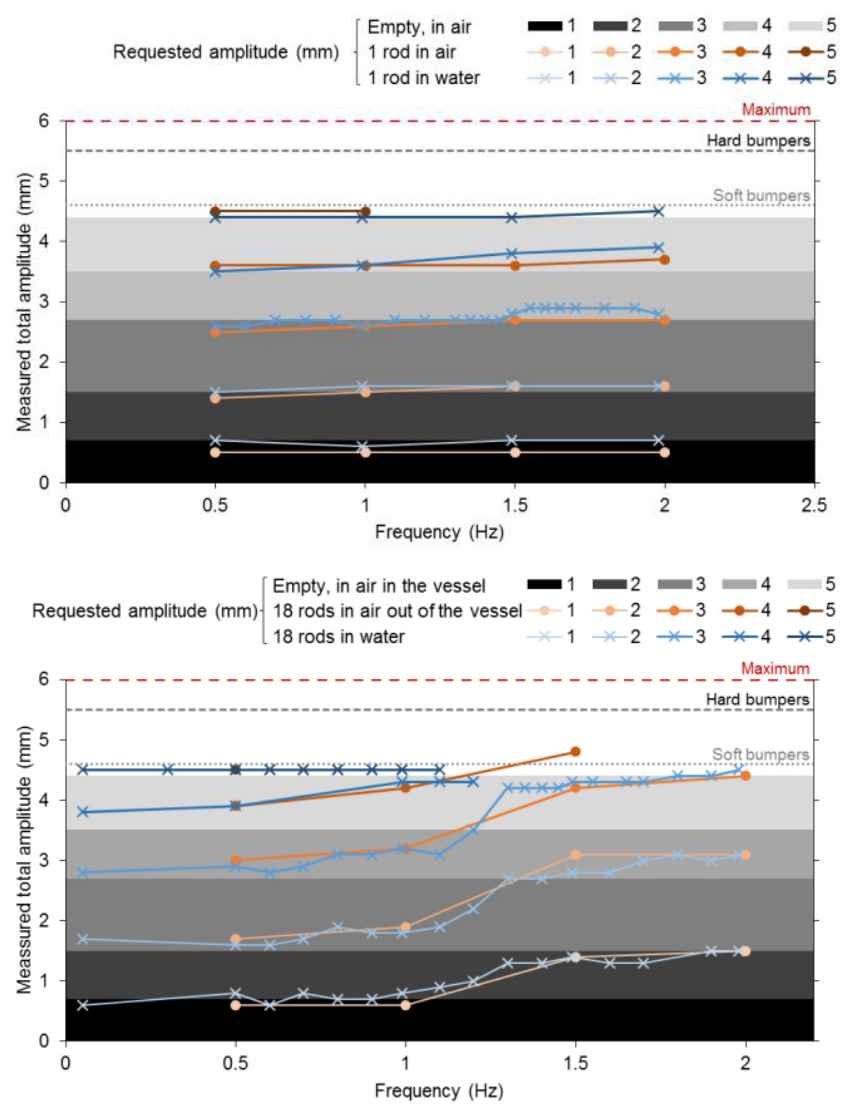

Fig. 7. Comparison of the oscillator behavior in water and in air, for one rod loaded (top), and 18 rods loaded (bottom). The points are connected for readability purposes.

\section{Discussion}

The results in amplitude for all tests in water are the reference for the COLIBRI experiments. They are summarized in Figure 8. Regarding the impact of the load, we observe a clear separation between the empty/1-rod loads and the 18-rods load: it is more progressive with frequency at lower amplitudes, but it always leads to a maximal addition of around $1.5 \mathrm{~mm}$ in the total course. As a consequence, the \pm 2.0 and $\pm 2.5 \mathrm{~mm}$ case would be limited in operation for safety purposes at 1.0 and $1.1 \mathrm{~Hz}$, respectively, for all loads to be conservative.

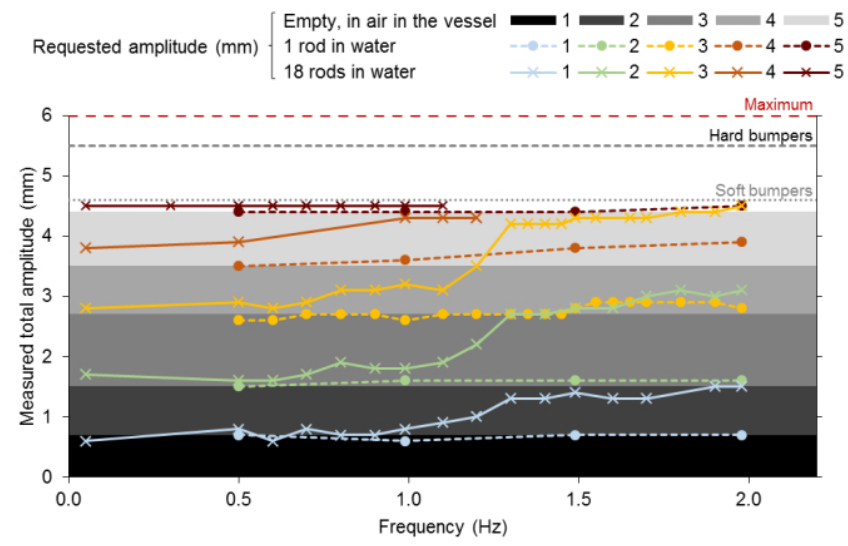

Fig. 8. Comparison of the behavior of the oscillator in water for one and 18 fuel rods loaded. The points are connected for readability purposes.

The defined operation range is presented in Table I. We assume that the behavior of the fuel rods oscillator is validated and characterized in amplitude and frequency within this whole range. Frequencies above $2 \mathrm{~Hz}$ were not considered, as the frequency of interest for nuclear power plants is around one $\mathrm{Hz}$, and the transfer function of CROCUS does not vary significantly in the closest superior range.

TABLE I

VALIDATED AND CHARACTERIZED OPERATION RANGE

\begin{tabular}{ccccccc}
\hline & \multicolumn{7}{c}{ Frequency } \\
$\begin{array}{c}\text { Amplitude } \\
(\mathrm{mm})\end{array}$ & Below & 0.5 & 1.0 & 1.5 & 2.0 & Above \\
& & & & & & \\
\hline \pm 0.5 & $\checkmark$ & $\checkmark$ & $\checkmark$ & $\checkmark$ & $\checkmark$ & $?$ \\
\pm 1.0 & $\checkmark$ & $\checkmark$ & $\checkmark$ & $\checkmark$ & $\checkmark$ & $?$ \\
\pm 1.5 & $\checkmark$ & $\checkmark$ & $\checkmark$ & $\checkmark$ & $\checkmark$ & $?$ \\
\pm 2.0 & $\checkmark$ & $\checkmark$ & $\checkmark(1.1)$ & $X$ & $X$ & $X$ \\
\pm 2.5 & $\checkmark$ & $\checkmark$ & $\checkmark(1.0)$ & $X$ & $X$ & $X$ \\
\hline \hline
\end{tabular}

$\checkmark$ : Validated; $X$ : Invalidated; ?: Not tested; (value) : maximum frequency.

\section{CONCLUSION AND OUTLOOK}

The mechanical behavior of the fuel rods oscillator developed for the purposes of the COLIBRI experimental program in CROCUS was characterized, out-of-pile and in-pile, both in air and in water, and as a function of the load, for safety and experimental purposes. The experimental device allows simultaneously oscillating up to 18 fuel rods. The behavior in frequency is sound, without any observations of abnormal harmonics. In amplitude, it demonstrates increased amplitudes at the bottom of the fuel for the full 18-rods load case and above $1 \mathrm{~Hz}$. Based on the obtained results, an operation range was defined, awaiting final approval from the Swiss regulator, IFSN/ENSI. The maximum allowed amplitude is $\pm 2.5 \mathrm{~mm}$, i.e. $5 \mathrm{~mm}$ total, while the maximum allowed frequency is $2 \mathrm{~Hz}$, i.e. in the frequency range in which the induced neutron flux fluctuations are most pronounced in nuclear power plants. The first COLIBRI neutron noise experimental campaign was successfully carried out in 2018 within the framework of the Horizon 2020 European project CORTEX. Following the ongoing analysis of the collected data, the next CORTEX campaign is planned for the end of 2019 . 


\section{ACKNOWLEDGMENT}

The authors would like to thank the CROCUS operation team for the help and dedication to the experiments.

\section{REFERENCES}

[1] C. Demazière, P. Vinai, M. Hursin, S. Kollias, and J. Herb, "Overview of the CORTEX project," in PHYSOR 2018: Reactor Physics Paving The Way Towards More Efficient Systems, 2018, pp. 2971-2980.

[2] V. Lamirand, M. Hursin, A. Rais, S. Hübner, C. Lange, J. Pohlus, U. Paquee, C. Pohl, O. Pakari, and A. Laureau, "Experimental report of the 1st campaign at AKR-2 and CROCUS," 2018.

[3] V. Lamirand, A. Rais, S. Hübner, C. Lange, J. Pohlus, U. Paquee, C. Pohl, O. Pakari, P. Frajtag, D. Godat, M. Hursin, A. Laureau, G. Perret, C. Fiorina, and A. Pautz, "Neutron noise experiments in the AKR-2 and CROCUS reactors for the European project CORTEX," in ANIMMA 2019, 2019.

[4] A. Rais, O. Pakari, A. Laureau, J. Pohlus, C. Pohl, V. Lamirand, M. Hursin, and A. Pautz, "Towards the validation of neutron noise simulators: qualification of data acquisition systems."

[5] V. Lamirand, P. Frajtag, D. Godat, M. Hursin, G. Perret, O. V. Pakari, A. Laureau, A. Rais, C. Fiorina, M. Chadwick, and A. Pautz, "The COLIBRI programme in CROCUS: development and licensing of a fuel rods oscillator," in RRFM/IGORR 2019, 2019.

[6] A. Rais, D. Siefman, G. Girardin, M. Hursin, and A. Pautz, "PARCS Few-group Homogenized Parameters Generation using Serpent Monte Carlo code at the CROCUS Reactor," in IGORR 2014, 2014, pp. 1-11.

[7] M. Hursin, A. Rais, D. Siefman, G. Girardin, and A. Pautz, "Verification of a reactor physics calculation scheme for the CROCUS reactor," in International Technical Meeting on Small Reactors, 2014, pp. 3-8.

[8] A. Rais, D. Siefman, G. Girardin, M. Hursin, and A. Pautz, "Methods and Models for the Coupled Neutronics and Thermal-Hydraulics Analysis of the CROCUS Reactor at EFPL," Sci. Technol. Nucl. Install., vol. 2015, 2015.

[9] D. J. Siefman, G. Girardin, A. Rais, A. Pautz, and M. Hursin, "Full Core modeling techniques for research reactors with irregular geometries using Serpent and PARCS applied to the CROCUS reactor," Ann. Nucl. Energy, vol. 85, pp. 434-443, 2015.

[10] V. Lamirand, M. Hursin, G. Perret, P. Frajtag, O. Pakari, and A. Pautz, "Future experimental programmes in the CROCUS reactor," in RRFM/IGORR 2016, 2016, no. 02-2016, pp. 284-292.

[11] A. Rais, M. Hursin, G. Perret, and A. Pautz, "Experimental validation of control rod reactivity worth and fission rate distributions for the CROCUS Reactor," Phys. React. 2016, PHYSOR 2016 Unifying Theory Exp. 21st Century, vol. 6, pp. 1-10, 2016.

[12] A. Rais, "Performance Assessment of a 3-D Steady-State and Spatial Kinetics Model for the Crocus Reactor," Ecole Polytechnique Fédérale de Lausanne (EPFL), 2017.

[13] O. Pakari, V. Lamirand, G. Perret, and A. Pautz, "Current Mode Neutron Noise Measurements in the Zero Power Reactor CROCUS," in ANIMMA 2017, 2017.

[14] O. Pakari, V. Lamirand, G. Perret, P. Frajtag, and A. Pautz, "Kinetic Parameter Measurements in the CROCUS Reactor Using Current Mode Instrumentation," IEEE Trans. Nucl. Sci., vol. 65, no. 9, pp. 2456-2460, 2018.

[15] V. Lamirand, G. Perret, S. Radman, D. Siefman, M. Hursin, P. Frajtag, A. Gruel, P. Leconte, P. Blaise, and A. Pautz, "Design of separated element reflector experiments in CROCUS: PETALE," React. Dosim. 16th Int. Symp. ASTM STP1608, p. 7, 2018.

[16] O. Pakari, V. Lamirand, G. Perret, D. Godat, M. Hursin, P. Frajtag, and A. Pautz, "Investigation of spatial effects on neutron noise measurements in the zero power reactor CROCUS," in Proceedings of PHYSOR 2018, 2018, p. 12.

[17] V. Lamirand, G. de Izarra, A. Krasa, G. Perret, O. V. Pakari, M. Hursin, P. Blaise, J. Wagemans, and A. Pautz, "Intercomparison of neutron noise measurement systems in the CROCUS reactor," in Proceedings of PHYSOR 2018, 2018, p. 11.

[18] M. Hursin, C. Weiss, P. Frajtag, V. Lamirand, G. Perret, P. Kavrigin, A. Pautz, and E. Griesmayer, "Testing of a SCVD diamond detection system in the CROCUS reactor," Eur. Phys. J. A, vol. 54, no. 5, 2018.
[19] A. Laureau, V. Lamirand, D. Rochman, and A. Pautz, "Total Monte Carlo acceleration for the PETALE experimental programme in the CROCUS reactor," EPJ Web Conf., vol. 211, p. 03002, Jun. 2019.

[20] V. Lamirand, A. Laureau, D. Rochman, G. Perret, A. Gruel, P. Leconte, P. Blaise, and A. Pautz, "An Experimental Programme optimized with Uncertainty Propagation: PETALE in the CROCUS Reactor," EPJ Web Conf., vol. 211, p. 03003, Jun. 2019.

[21] Y. Jiang, A. Laureau, V. Lamirand, P. Frajtag, and A. Pautz, "In-core dosimetry for the validation of neutron spectra in the CROCUS reactor," in ANIMMA 2019, 2019.

[22] O. Pakari, V. Lamirand, B. Vandereyt, F. Vitullo, M. Hursin, C. Kong, and A. Pautz, "Design and simulation of gamma spectrometry experiments in the CROCUS reactor," in ANIMMA 2019, 2019.

[23] F. Vitullo, V. Lamirand, J.-B. Mosset, P. Frajtag, O. Pakari, G. Perret, and A. Pautz, "A miniature fiber-coupled scintillator for in-core neutron counting in CROCUS," in ANIMMA 2019, 2019.

[24] V. Lamirand, "Experiments in a ZPR in the 2010s : Harvesting data in CROCUS," in ANIMMA 2019 - Workshop $N^{\circ} 1$ "The coupling of experiments and modelling to enhance experiments in research reactors," 2019.

[25] U. Kasemeyer, R. Früh, J. M. Paratte, and R. Chawla, "Benchmark on Kinetic Parameters in the CROCUS Reactor," in International Reactor Physics Experiments Handbook (IRPhE), no. 4440, OECD, Ed. 2007, p. 94

[26] J. M. Paratte, R. Früh, U. Kasemeyer, M. a. Kalugin, W. Timm, and R. Chawla, "A benchmark on the calculation of kinetic parameters based on reactivity effect experiments in the CROCUS reactor," Ann. Nucl. Energy, vol. 33, no. 8, pp. 739-748, May 2006.

[27] K. Macku, "Permis d'exécution pour l'installation d'un dispositif d'oscillation du combustible dans CROCUS, programme expérimental COLIBRI,” IFSN MAK/GUJ-25/18/001, 2018. 